\title{
Reproductive ecology of a Tibetan frog Nanorana parkeri (Anura: Ranidae)
}

\author{
Xin Lu, Xiaoyan Ma, Liqing Fan, Yigang Hu, Zedong Lang, Zhibin Li, Bohao Fang \\ and Weibin Guo
}

Department of Ecology, College of Life Sciences, Institute for Advanced Studies, Wuhan University, Wuhan, China

\begin{abstract}
Endemic to the Tibetan Plateau, Nanorana parkeri figures among the highest altitude amphibians in the world. The present work, which was conducted in an alpine marsh at $4300 \mathrm{~m}$ altitude, is the first report of the species' reproductive ecology. The breeding season, as indicated by the presence of amplectant pairs and fresh eggs in ponds, lasted from early Mary to early July. The ratios of adult male to female were 1.3 in hibernation ponds and 2.3 in spawning ones. Males were smaller than females. Amplexus was typically axillary (81.7\%), with a few exceptional amplexus in which a male clasped another male or object rather than gravid females. Scramble competition occurred in $6.8 \%$ of the normal amplexus located. The body sizes of amplexed couples correlated positively. Deposited eggs were attached to submerged plants solitarily $(60.5 \%)$ or in small clusters $(39.5 \%)$, and the scattered arrangement of individual eggs could be a strategy to ensure embryonic development in oxygen-poor environments. Clutch size averaged 189 [standard deviation $(S D)=64$ ], and correlated positively with female body size; egg size averaged $2.18 \mathrm{~mm}(\mathrm{SD}=0.10)$, independent of female body size; both traits within a clutch were negatively related with each other even controlling for female body size. Relatively few and large eggs laid by the Tibetan frogs, compared with those by lowland aquatic-spawning anuran species, should be adaptive to the harsh high-altitude conditions. Larvae hatched from eggs after 16.4 days on average (SD = 5.8). Froglets emerged between late July and early August, but some tadpoles were present in winter. These findings may help to understand the evolution of amphibians in extreme environments and to protect these remote species.
\end{abstract}

\section{ARTICLE HISTORY}

Received 19 January 2016

Accepted 17 June 2016

\section{KEYWORDS}

Clutch size; egg size; high altitude; life history; social system; spawning behaviour

\section{Introduction}

Among the more than 7513 currently recognised species of amphibians in the world (Frost 2016), only a few are found at altitudes of more than $3000 \mathrm{~m}$. To survive challenging highaltitude conditions typically characterised by low temperatures, poor oxygen availability, strong solar radiation and limited food resources, these animals must display adaptations

CONTACT Xin Lu luxinwh@163.com EDepartment of Ecology, College of Life Sciences, Institute for Advanced Studies, Wuhan University, Wuhan, China 
in aspects of morphology, physiology, ecology and behaviour (Navas 2002). On the other hand, alpine amphibians are particularly sensitive to global climatic warming, as shown by some patterns. For example, three Andean species have extended their altitudinal limits in response to recent glacial recession, and two of these species have been infected with Batrachochytrium dendrobatidis (Longcore et al. 1999) (Seimon et al. 2007), a fungal pathogen involved in global amphibian declines (Kilpatrick et al. 2010).

The Tibetan Plateau provides a vast high-altitude environment. Relative to the tropical high-altitude Andes, climate conditions in the plateau, especially temperature and humidity, seem to be even harsher for amphibians. Consequently, only 10-12 Tibetan species reach altitudes of more than $3000 \mathrm{~m}$ (Hu 1987; Fei et al. 2009), in contrast to at least 40 species in the equatorial Andes (Navas 2002). Reproduction represents a critical stage of the life cycle of any organism. Therefore, knowledge on the reproductive ecology of high-altitude amphibians may enhance understanding of amphibian evolution in extreme environments and help to guide the conservation of these remote species. Most of what is known on this topic comes from studies on Andean species (e.g. Lüddecke 2002; Navas 2002), and information for Tibetan species is very rare (Lu et al. 2008; Yu and Lu 2012; Chen et al. 2013).

Nanorana parkeri (Stejneger 1927) is a ranid frog endemic to the southern Tibet Plateau, where it occupies a relatively narrow latitudinal $\left(28\right.$ to $\left.31^{\circ} \mathrm{N}\right)$ and longitudinal ( 84 to $97^{\circ} \mathrm{E}$ ) range that contrasts with the broad altitudinal distribution ( 2850 to $5100 \mathrm{~m}$; Fei et al. 2009). The frogs inhabit open alpine marshes and rivers where they are the most abundant local amphibians, so that they are ecologically successful in such extreme environments. We have reported on demography of this frog, including age structure, growth rate and sexual size dimorphism (Ma and Lu 2009; Ma et al. 2009; Zhang et al. 2012), showing that age at maturity ranges between 2 and 6 years, females (5.7 years $\pm 1.7,2-11$ years) live longer than males (5.3 years $\pm 1.4,2-10$ years), and body sizes of female frogs decrease along altitudinal gradients more rapidly than those of male frogs because of slowed growth in the former compared with the latter. Based on an analysis of the ovarian cycle and spermatogenic dynamics, Ma and Lu (2010) suggested that females could reproduce biennially, whereas males do so annually. However, the reproductive ecology of $N$. parkeri, including spawning season, habitat requirement, egg and clutch parameters, and mating system, remains unknown. The present study provides such information, aiming to enhance knowledge on the natural history of high-altitude frogs, and to learn about anuran life-history shifts along altitudinal gradients. In addition, we hope to aid the conservation of a species which, according to our observations (unpublished), has exhibited population decline in some localities, as has been the case of many anurans, especially those residing in relatively pristine habitats (Catenazzi 2015).

\section{Materials and methods}

\section{Study area}

Fieldwork was conducted from April to July of 2006 to 2008 in Damxung marshes, southern Tibet $\left(30^{\circ} 29^{\prime} \mathrm{N}, 91^{\circ} 05^{\prime} \mathrm{E}\right.$; Figure 1). The long-term annual average temperature at this site of $4300 \mathrm{~m}$ altitude is $1.3^{\circ} \mathrm{C}$, with sub-zero monthly means between November 


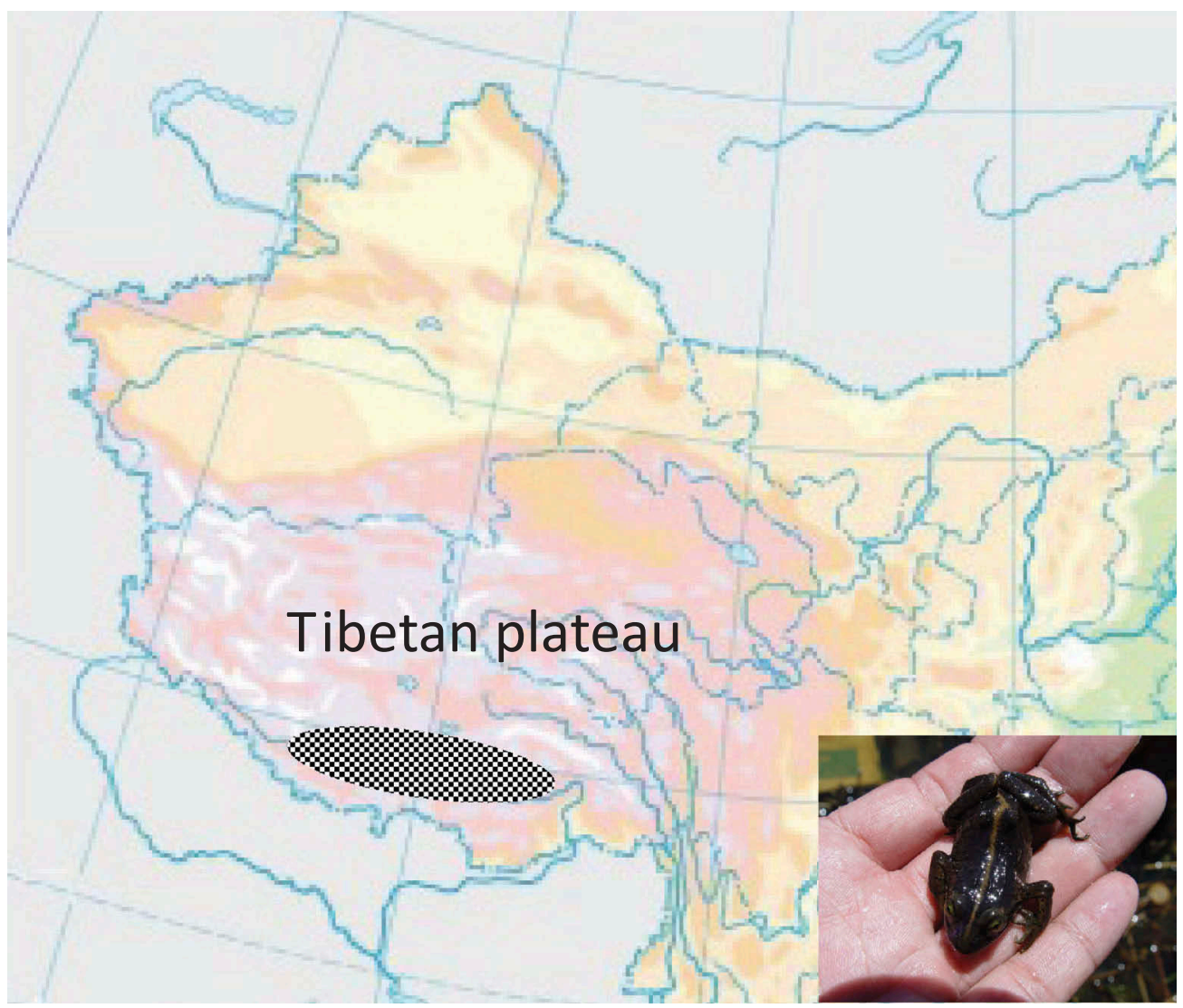

Figure 1. Map showing the species distribution and study site.

and March. The annual total precipitation is $483 \mathrm{~mm}$, with $86 \%$ falling between June and September. Solar radiation (annual sunshine duration up to 2881 hours) is strong.

A study plot of $100 \mathrm{~m} \times 55 \mathrm{~m}$ was set in the marsh habitat (Figure 2). Within the plot there were $\sim 50$ ponds differing in water source, $11 \mathrm{fed}$ by permanent springs $\left(0.4-7.6 \mathrm{~m}^{2}\right.$ in size, $9.8-27.0 \mathrm{~cm}$ in depth), and the remaining $\sim 40$ ponds by rainfall $\left(0.5-6.3 \mathrm{~m}^{2}\right.$ in size, $3.3-18.5 \mathrm{~cm}$ in depth). Frogs hibernated in seven of the permanent ponds and used the remainder for spawning. Aquatic vegetation in spawning ponds consisted mainly of several species in the genera Potamogeton and Halerpestes. The terrestrial substrate around the ponds was dominated by the alpine grass in the genus Kobresia. Fish (Triplophysa spp.) occurred commonly in the hibernation ponds but were rare in the spawning ponds. In addition to N. parkeri, the toad species Scutiger boulengeri (Bedriaga 1898) occurs at the study site, but its population densities are much lower (only four individuals were seen during this study).

\section{Field survey}

Adult and juvenile frogs along with a few tadpoles hibernated in the permanent ponds where they crowd under water on the bottom along the edge of the ponds. In April 

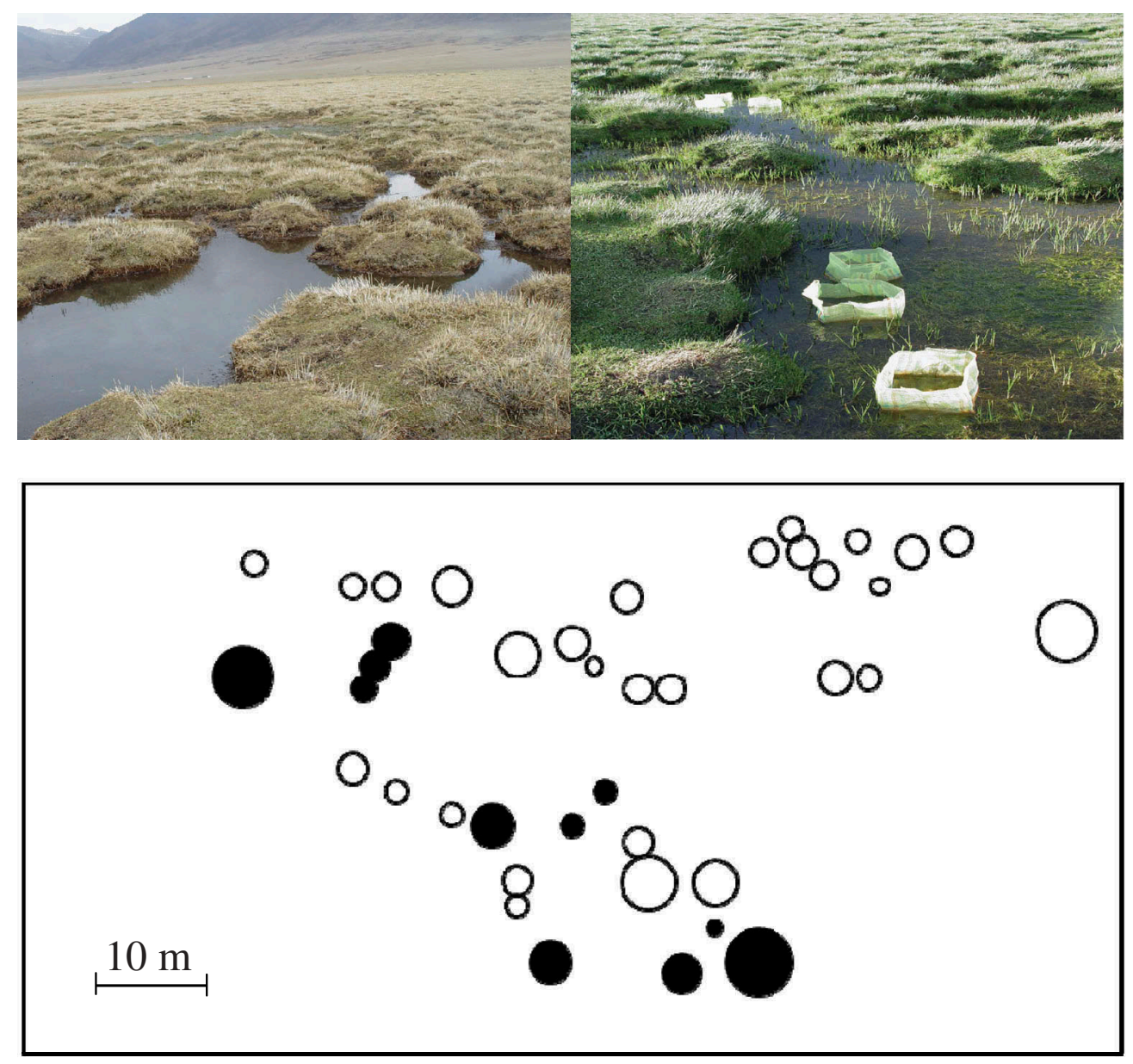

Figure 2. Typical habitats used by the frogs, and spatial locations of the hibernation (closed circles) and spawning (open circles) ponds in the study plot $(100 \times 55 \mathrm{~m})$. Sizes of the circles represent pond area.

before the frogs moved to the breeding ponds, we captured hibernating individuals at each pond by hand. These animals were held in a pail containing pond water and transported to the field laboratory (50 $\mathrm{m}$ away from the study plot) for measurement. For each specimen, we measured snout-vent length (SVL, with digital callipers to the nearest $0.1 \mathrm{~mm}$ ) and body mass (with an electronic balance to $0.1 \mathrm{~g}$ ). Adult males were identified by the dark-coloured nuptial pads on their thumbs, but females and juveniles could not be told apart just by appearance. Therefore, we treated non-male individuals with an SVL greater than $27.3 \mathrm{~mm}$ (the minimum SVL of females in amplexus) as adult females. After measuring, we returned individuals to their hibernation ponds. No individual was marked, because of the absence of an effective marking technology.

During the breeding period, we visited the plot daily, mainly in the afternoon (1700 to $1900 \mathrm{~h}$ ) and evening ( 2100 to $2400 \mathrm{~h}$, using a battery lamp), to record the number of non-mated individuals, amplectant pairs, and occurrence of fresh eggs. In parallel, we observed opportunistically all behavioural interactions (males do not give advertisement 
calls because they have no vocal sacs). In eight randomly selected ponds, we estimated the density and sex ratio of adult frogs by capturing individuals $2-3$ hours before sunset (around $1800 \mathrm{~h}$ ), and identifying their age and sex. We also collected amplectant pairs and transported them (each in a cloth bag) to the laboratory, where we measured SVL and body mass in case males and females separated during the operations. Otherwise, pairs were measured after oviposition.

Egg deposition pattern was estimated by considering eggs unconnected to any neighbour egg through the coating jelly (single eggs), and two or more eggs in contact, attached by jelly (aggregated eggs). We also measured the water depth at which eggs were deposited, and the distance between eggs and the water surface. To avoid repeated sampling we selected only freshly deposited eggs. We also marked 20 fresh eggs and regularly monitored their development until the embryos hatched (Gosner stage 25; Gosner 1960).

We randomly chose 51 amplectant pairs and transported them (each in a cloth bag) to the laboratory, where we placed each pair in a tank $(40 \mathrm{~cm} \times 50 \mathrm{~cm} \times 60 \mathrm{~cm})$ filled with water (5-10 cm in depth) and grass submerged in water to favour spawning. We counted the total numbers of eggs laid and, from each clutch, we selected randomly some eggs ( $46 \%$ of the total numbers of eggs on average, $23-86 \%, n=46$ clutches) and placed them on a white plate with a ruler (the minimum scale $0.05 \mathrm{~mm}$ ) to take a picture using a digital camera. Egg size was measured based on the digital pictures using the Motic Images software (version 3.2).

Tadpoles were randomly captured in hibernation ponds in April and May when we investigated population structure, and in spawning ponds in early July, late August and early October. The hind limb length of these tadpoles was measured to the nearest $0.1 \mathrm{~mm}$.

Field and laboratory manipulations did not result in injuries or death of animals. Individual frogs, eggs and tadpoles, once processed as described, were returned to their ponds of origin. During field work, maximum efforts were made not to disturb the animals.

\section{Data analysis}

Data from the three breeding seasons were pooled unless specified. We ran Chi-square tests to assess the sex ratio of adult animals, and ran independent-samples and pairedsamples $t$ tests to compare the differences in mean body sizes between individuals of different sexes or social status. We applied Pearson correlation, or in some cases partial correlation, to estimate the relationship between amplectant male and female body sizes, between clutch and egg size, and between the last-mentioned variables and body size and season. Prior to analyses, raw data were $\log _{10}$-transformed to meet the assumptions of linearity. Two-tailed significance levels were set at 0.05 . Data are presented as means \pm standard deviation (SD).

\section{Results}

\section{Breeding season}

Frog migration from hibernation to breeding ponds was initiated in late April (based on dates of the earliest emergence of frogs on the breeding ponds). During early breeding 


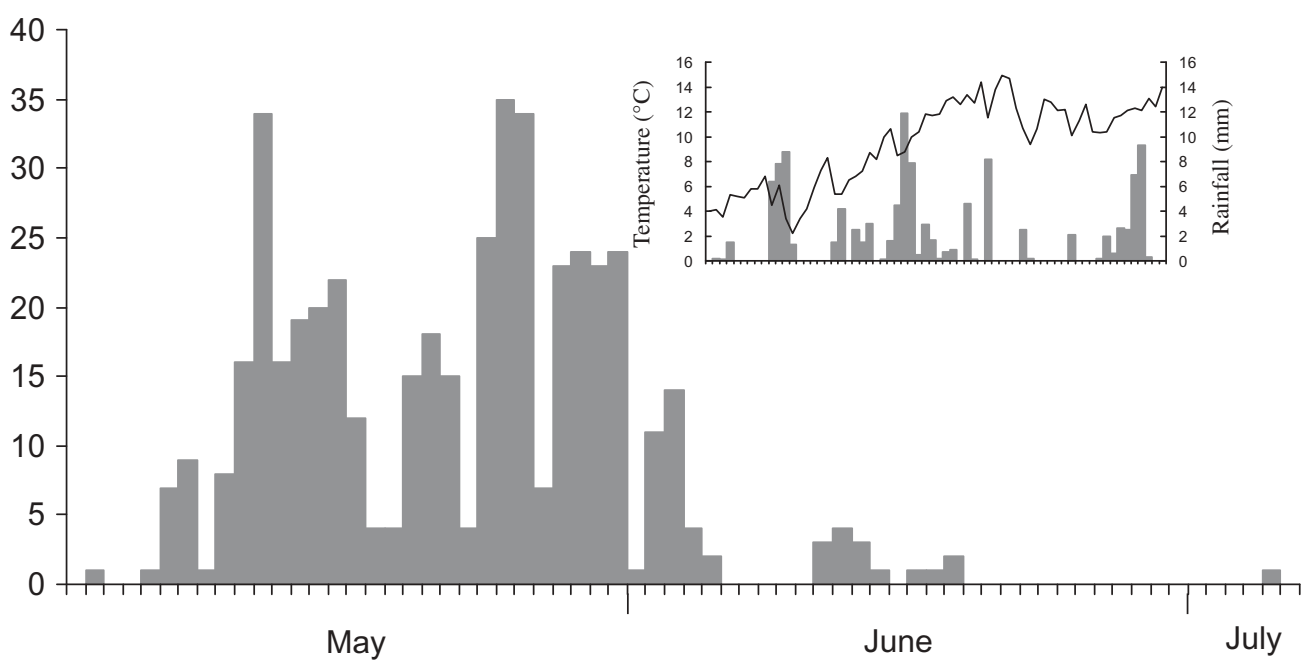

Figure 3. Breeding chronology (the number of amplectant pairs observed per day) of the frogs in relation to ambient temperature and rainfall during the 2007 breeding season.

season, hibernation ponds were ice-covered most time of the day, but ice melted by midday (1100 to $0100 \mathrm{~h}$ ), which made daily migration more likely to occur. Amplectant pairs in breeding ponds were found between 2 May and 4 July, and fresh eggs between 1 May and 6 July. The daily probability of finding amplexus coincided with fluctuations of rainfall (Figure 3 ).

\section{Age structure, sex ratio and density of the breeding population}

Of 2990 metamorphosed individuals observed in hibernation ponds, 1353 (45.3\%) were adults and 1637 (54.7\%) juveniles. The sex ratio of hibernating adults was male biased (754 males/598 females $=1.26)$. A few tadpoles $(n=18)$ were detected in the hibernation ponds. It is possible that these tadpoles entered the hibernation ponds from the breeding ponds when flood occurred.

During the breeding season, the frogs were active both day and night. Densities of non-amplectant individuals in the breeding ponds ranged from 0 to 11 frogs per $\mathrm{m}^{2}$ water area ( $6.0 \pm 3.6$ frogs per $\mathrm{m}^{2}$ water area, $n=8$ ponds). All these individuals were adult males, most of which rested on the water surface, whereas a few hid under water or on land. At night, more non-amplectant individuals were found (17.1 \pm 4.9 frogs per $\mathrm{m}^{2}, 9-28$ frogs per $\mathrm{m}^{2}, n=10$ ponds), which included both males and females (sex ratio $=2.29 \pm 0.74,1.38-4.00)$.

\section{Pairing pattern in relation to body size}

Adult males ( $36.5 \pm 2.83 \mathrm{~mm}, 25.1-47.6 \mathrm{~mm}, n=754$ ) in hibernation ponds were smaller than adult females $(41.4 \pm 5.5 \mathrm{~mm}, 29.2-59.9 \mathrm{~mm}, n=598)(t=19.73, d f=1351, P<0.001)$, even when considering only paired individuals (male: $35.9 \pm 2.48 \mathrm{~mm}, 28.4-45.6 \mathrm{~mm}$, $n=465$; female: $43.8 \pm 4.38 \mathrm{~mm}, 27.3-55.9 \mathrm{~mm}, n=465$; paired-samples test, $t=33.58$, 


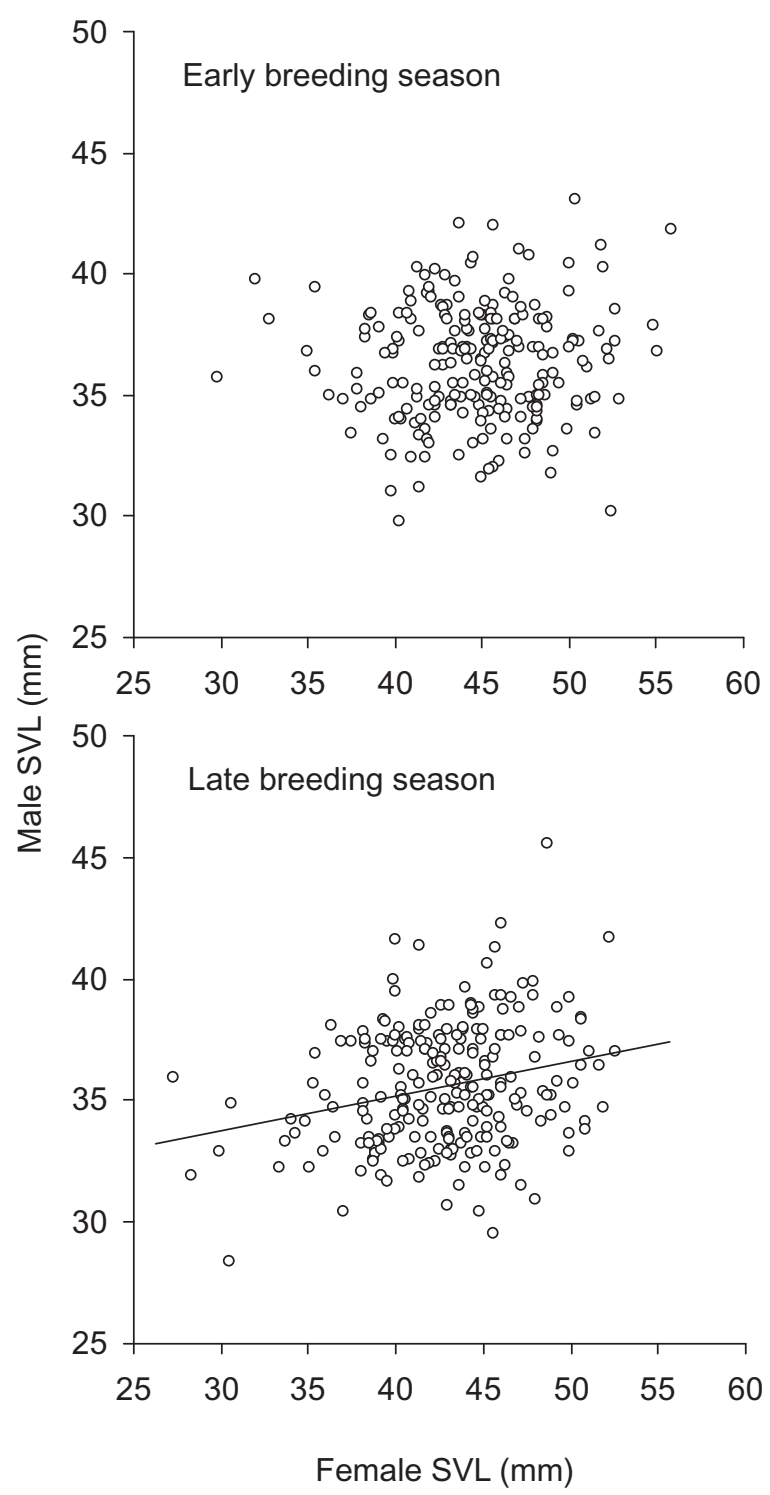

Figure 4. Plots of body size of males and females in amplexus found in early and late breeding season. SVL: snout-vent length.

$d f=464, P<0.001)$. The SVLs of paired males and females correlated positively $(r=0.19$, $n=465, P<0.001$ ), but this correlation was absent when considering only pairs found in the early breeding period (1-31 May; $r=0.06, n=227, P=0.36$ ). Therefore, this relationship became evident in the late breeding period (1 June to 4 July; $r=0.25, n=238, P<0.001$; Figure 4). Both males and females in amplexus tended to be smaller as the season progressed (male, $r=-0.11, n=465, P=0.017$; female, $r=-0.19, n=465, P<0.001$ ).

Amplexus was typically axillary in most cases $(81.7 \%)$, with a few examples of exceptional amplexus (18.3\%; Table 1). Male-male amplexus generally were unstable and shortlasting (often separated when caught or measured), but 11 out of the 61 male-male 
Table 1. Frequency distribution of normal and abnormal amplexus.

\begin{tabular}{lrr}
\hline Object clasped & $n$ & $\%$ \\
\hline Gravid female in typical amplexus & 398 & 81.7 \\
Gravid female in atypical amplexus* & 16 & 3.3 \\
Dead female & 8 & 1.6 \\
Conspecific male & 61 & 12.5 \\
Toad & 2 & 0.4 \\
Fish & 1 & 0.2 \\
Yak faeces & 1 & 0.2 \\
Total & 487 & 100.0 \\
\hline
\end{tabular}

*Inguinal $=4$, ventral $=9$, cephalic $=3$.

amplexus exceeded $60 \mathrm{~min}$ in duration (from first sight to separation). For 47 male-male amplexus, the clasping males $(34.9 \pm 2.8 \mathrm{~mm}, 29.6-42.0 \mathrm{~mm}$ ) were significantly smaller than the clasped males $(39.3 \pm 3.4 \mathrm{~mm}, 33.3-48.1 \mathrm{~mm}$; paired-samples test, $t=7.98, d f=46$, $P<0.001)$, and the former were significantly smaller than males that normally clasped females $(t=2.68, d f=510, P=0.008)$. There was a nearly significant positive correlation between the two males in amplexus $(r=0.25, n=47, P=0.09)$.

We recorded 27 male scramble competitions (6.8\% of the 398 matings located), which involved one to 5 males $(1.26 \pm 0.86)$ attempting to dislodge the amplexing male. Five scrambles lasted over 2 hours and there was no indication of take-over success. The attacking males in scramble competitions had SVLs $(36.0 \pm 3.4 \mathrm{~mm}, 29.6-44.8 \mathrm{~mm}$, $n=32)$ similar to those $(35.3 \pm 2.5 \mathrm{~mm}, 31.2-42.3 \mathrm{~mm}, n=26)$ of the original males $(t=0.32, d f=56, P=0.75)$.

\section{Egg deposition pattern}

Most eggs (82.7\% of 971 estimated) were attached to submerged plants, and a few (17.3\%) on the bottom of ponds. In $60.5 \%$ cases, deposited eggs existed solitarily, $39.3 \%$ in clump of 2-10 eggs, and only $0.2 \%$ in clump of more than 10 eggs (Figure 5). Water depth of the placements where eggs were staying ranged from 2 to $26 \mathrm{~cm}$, with $95.4 \%$ of the 971 locations estimated $<10 \mathrm{~cm}, 4.1 \%$ between 10 and $20 \mathrm{~cm}$ and $0.5 \%>20 \mathrm{~cm}$.

\section{Egg and clutch parameters}

Among 51 amplectant pairs collected from the wild, 46 completed oviposition in laboratory. About half (22) of these 46 females deposited their eggs successively, whereas others (24) did so in bouts $(1.9 \pm 1.0,1-5)$, with a total duration of spawning from several hours to 4 days. Some females only laid a few eggs in the laboratory (65.3 \pm 19.4 eggs, 33-97 eggs, $n=17$ ), more likely because they had spawned a portion of eggs in the wild before being caught. When calculating clutch size, we did not include pairs producing less than 102 eggs, the smallest clutch size according to dissection before the spawning period. Clutch size ranged from 103 to 399 eggs ( $189 \pm 64$ eggs, $n=29$ ), positively correlating with female body size $(r=0.63, n=29, P<0.001)$. Egg size averaged $2.18 \pm 0.10 \mathrm{~mm}(1.99-2.39 \mathrm{~mm}$, $n=29$ clutches), independent of female body size $(r=-0.01, n=29, P=0.94)$; this was the case when using data from all pairs that laid in laboratory $(2.22 \pm 0.16 \mathrm{~mm}, 1.94-2.76 \mathrm{~mm}$, $n=46$ clutches: $r=0.13, P=0.39)$. Clutch size and egg size correlated negatively $(r=-0.51$, 


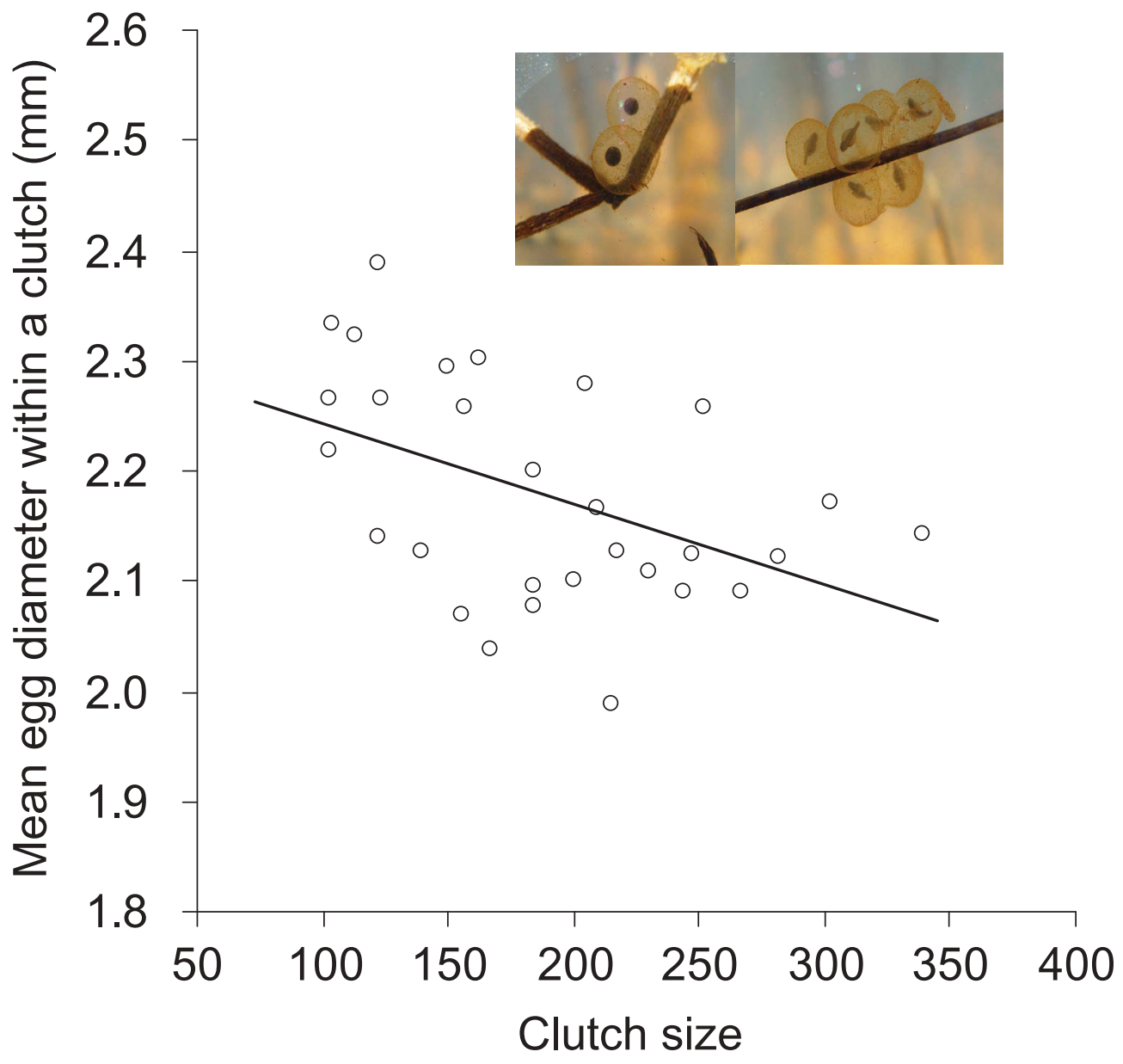

Figure 5. Relationship between clutch size and egg size.

$n=29, P=0.005$; Figure 5), even when controlling for female body size (partial correlation coefficient, $r=-0.64, d f=26, P<0.001$ ).

Intraclutch variation in egg size, expressed by the coefficient of variation, ranged from 1.99 to $10.55(5.01 \pm 1.84, n=46)$. The degree of variance in egg size was unrelated with female SVL $(r=0.20, P=0.18)$ or mean egg size $(r=-0.10, P=0.50)$, but tended to increase with clutch size $(r=0.29, P=0.07)$.

\section{Development of embryo and larva}

Of 20 marked and monitored eggs in the wild, 80\% (16) survived to Gosner stage 25; the value was $74 \%$ (67) for 90 eggs laid in the laboratory. The development time of embryos, the number of days elapsed between first laying and attainment of Gosner stage 25 , lasted 16.4 days ( $\pm 5.8,12-29$ days, $n=16$ marked eggs), tending to be short if eggs were laid late in the breeding season $(r=0.88, n=16, P<0.001)$. Eggs 
Table 2. Frequency distribution of hind limb length of tadpoles found in different periods of seasonal time.

\begin{tabular}{lcccc}
\hline Hind limb length $(\mathrm{mm})$ & April-May & Early July & Late August & Early October \\
\hline 0 & 0 & 11 & 4 & 0 \\
$0.1-5.0$ & 3 & 127 & 35 & 16 \\
$5.1-10.0$ & 1 & 34 & 3 & 5 \\
$10.1-15.0$ & 1 & 18 & 2 & 5 \\
$15.1-20.0$ & 0 & 1 & 0 & 1 \\
$20.1-22.6$ & 0 & 0 & 1 & 0 \\
Total & 5 & 191 & 45 & 27 \\
\hline
\end{tabular}

laid in laboratory took $18.3 \pm 4.0$ days (12-28 days, $n=67$ eggs) to complete embryo development.

Most froglets emerged during the period from late July to early August. However, field observations showed that some tadpoles overwintered together with adults and juveniles. The distribution of hind limb length of tadpoles (Table 2) suggested that overwintering tadpoles could be those that hatched late in the year.

\section{Discussion}

\section{Breeding season and oviposition pattern}

We showed that N. parkeri performed breeding activity over a period of 10-11 weeks, and can be classified as prolonged breeders (Wells 1977). Their ovipositing activity seemingly responded to rainfall, although the breeding ponds were fed with exuded ground water due to melting of mountainous snow. This differs from explosive breeders (e.g. Bufo bufo Linnaeus 1758: Reading 1998; Rana temporaria Linnaeus 1758: Scott et al. 2008; Rana chensinensis David 1875: Lu et al. 2009) at high latitudes or altitudes where temperature often is the sole determinant for breeding phenology. Nanorana parkeri were active during the day and night over the breeding season, as seen in some high-altitude anurans that are exposed to cold and fluctuating climates (Carey 1978; Sinsch 1989; Navas 1997). This indicates that the Tibetan frogs have a wide range of temperature in which activity is possible.

Females of $N$. parkeri scattered eggs individually or in small packets and attached them to aquatic vegetation. Such oviposition patterns are typically found in some species in the genera Pseudacris, Acris, Hyla, Spea and Xenopus (Altig and McDiarmid 2007; Wells 2007). Scattered eggs are assumed to have anti-predation advantages in terms of reduced conspicuousness and risk dilution (Rabb 1973), or enhanced effectiveness for gas exchange by maximising the exposed surface of eggs in oxygen-poor water (Seymour and Roberts 1995; Seymour 1999). The latter case could be true for N. parkeri, which breed in extremely high altitudes where the oxygen content in air is only $60 \%$ of that at sea level. The observations that eggs were positioned nearly at the water surface might suggest a link with embryo respiration. However, if embryo respiration was the only selective pressure promoting the egg deposition strategy, one would expect that the Tibetan frogs would place all eggs on the water surface. This is not the case, as most eggs were immersed in water by attachment to aquatic plants. A possible or additional advantage of the egg deposition strategy could lie in avoidance of freezing damage, as suggested for some species living in cold regions (Frisbie et al. 2000). 


\section{Life history strategy}

Nanorana parkeri females, with an average SVL of $41 \mathrm{~mm}$, produced around 190 eggs with a diameter of $2.18 \mathrm{~mm}$, much smaller in clutch size but larger in egg size compared with the averages of 41 lowland anuran species with aquatic eggs (body size: $54 \mathrm{~mm}$; clutch size: $1513 \pm 2524,21-15000$; egg size: $1.78 \pm 0.79 \mathrm{~mm}, 0.75-$ $4.00 \mathrm{~mm}$; summarised from the data of Duellman and Trueb 1994). This pattern is consistent with life history theory, which argues that selection should favour allocation of reserves between offspring number and size in ways that maximise fitness (Smith and Fretwell 1974; Lu et al. 2010). Large eggs and the resultant large larvae have advantages for surviving harsh environments (Kaplan and King 1997). While harsh conditions at high altitudes have constrained the total investment by $N$. parkeri females in annual reproduction, they tend to reduce their clutch size to invest more in each offspring. The fecundity-size relationship along environmental gradients has been observed in some anuran species (Cummins 1986; Berven 1988; Lüddecke 2002; Liao et al. 2014), suggesting that harsh conditions prevent the two traits from increasing simultaneously.

Within-clutch variation in egg size (coefficient of variation) was $5 \%(2-11 \%)$ in $\mathrm{N}$. parkeri, larger than that reported for several lowland anuran species (Bombina orientalis Boulenger 1890: 1-3\%, Kaplan and King 1997; Ranidella signifera Girard 1853: 2\%, Williamson and Bull 1995). This suggests that the Tibetan frogs could use a bet-hedging strategy by increasing variation in individual fitness to deal with fluctuating and unpredictable environments (Crump 1984).

\section{Mating system}

The low explanatory power (3.6\%) of the variance in body size of paired N. parkeri individuals for the positive relationship between body sizes of males and females in amplexus suggests weak size-assortative mating. Size-assortative mating may be a result of sexual selection in which larger males over smaller ones have advantages to win intrasexual competition for access to mates and larger males are more likely to be preferred by females, leaving small ones to pair with each other (Crespi 1989). Therefore, the observed mating pattern suggests that sexual selection in N. parkeri is not extensive. Weak sexual selection in $N$. parkeri as a prolonged breeder may be associated with their less male-biased operational sex ratio (2.29:1) and low adult male density (12 frogs per $\mathrm{m}^{2}$ ), two critical factors that promote sexual selection (Sullivan 1985; Elmberg 1990; Kvarnemo and Ahnesjo 1996). In explosively breeding Rana chensinensis, where a strong size-assortative mating has been detected, the operational sex ratios are 15-28:1 and male densities are 10-26 frogs per $\mathrm{m}^{2}$ (Lu et al. 2009). A low rate of scramble competition (4.5\%) in N. parkeri, compared to 30-38\% in several explosively breeding anurans (Davies and Halliday 1979; Telford and Van Sickle 1989; Reading and Clarke 1983), also indicates less extensive male-male competition.

Size-assortative mating may arise if body sizes of both sexes covary through time (Crespi 1989). In N. parkeri, both breeding males and females tended to be smaller as the breeding season advanced. However, we failed to find a significant relationship between SVLs of amplectant males and females in the early breeding season. It was likely that 
other mechanisms promoting random mating had overwhelmed the effect of temporal distribution of breeding individuals.

In some anuran species, especially explosive breeders with high individual aggregation, males actively search for females and attempt to clasp any small objects moving nearby (Arak 1983), suggesting little selection pressure for sex recognition by males (Marco et al. 1998). It is unclear why male-male amplexus frequently occurred in the Tibetan frogs with a prolonged breeding strategy.

\section{Acknowledgements}

We are grateful to Dianhua Ke for his assistance in the field, and to Jonathan J. Fong and Carlos A. Navas for their helpful comments on earlier drafts of this paper. This work was conducted in the Field Research Station for Tibetan Wildlife, which is jointly administered by Wuhan University and Tibet University.

\section{Disclosure statement}

No potential conflict of interest was reported by the authors.

\section{Funding}

Financial support was provided by the National Science Foundation of China [grant numbers 30425036 and 31272308].

\section{References}

Altig R, McDiarmid RW. 2007. Morphological diversity and evolution of egg and clutch structure in amphibians. Herpetol Monogr. 21:1-32.

Arak A. 1983. Male-male competition and mate choice in anuran amphibians. In: Bateson P, editor. Mate choice. Cambridge (UK): Cambridge University Press; p. 181-210.

Bedriaga JV. 1898. Amphibien und Reptilien. Lfg. 1, Caudata, Eucaudata, in:'wissenschaftlische Resultate der von NM Przewalski nach Central-Asien unternommenen Reisen'. Zool Theil. 3:1-69.

Berven KA. 1988. Factors affecting variation in reproductive traits within a population of wood frogs (Rana sylvatica). Copeia. 1988:605-615.

Boulenger GA. 1890. A list of the reptiles and batrachians of Amoorland. Ann Mag Nat Hist Series. 6:137-144.

Carey C. 1978. Factors affecting body temperatures of toads. Oecologia. 35:197-219.

Catenazzi A. 2015. State of the world's amphibians. Annu Rev Env Resour. 40:91-119.

Chen W, Tang ZH, Fan XG, Wang Y, Pike DA. 2013. Maternal investment increases with altitude in a frog on the Tibetan Plateau. J Evol Biol. 26:2710-2715.

Crespi BJ. 1989. Causes of assortative mating in arthropods. Anim Behav. 38:980-1000.

Crump ML. 1984. Intraclutch egg size variability in Hyla crucifer (Anura: Hylidae). Copeia. 1984:302308.

Cummins CP. 1986. Temporal and spatial variation in egg size and fecundity in Rana temporaria. J Anim Ecol. 55:303-316.

David A. 1875. Journal de mon troisième voyage dans l'empire chinois. Paris: Bibliolife.

Davies NB, Halliday TR. 1979. Competitive mate searching in male common toads Bufo bufo. Anim Behav. 27:1253-1267. 
Duellman WE, Trueb L. 1994. Biology of amphibians. Baltimore (MD): Johns Hopkins University Press.

Elmberg J. 1990. Long-term survival, length of breeding season and operational sex ratio in a boreal population of common frogs Rana temporaria. Can J Zool. 68:121-127.

Fei L, Ye CY, Hu SQ, Tian WS, Jiang JP, Li J. 2009. Fauna Sinica, Amphibia Vol. 3: Anura Ranidae. Beijing: Science Press; p. 1847.

Frisbie MP, Costanzo JP, Lee RE Jr. 2000. Physiological and ecological aspects of low-temperature tolerance in embryos of the wood frog, Rana sylvatica. Can J Zool. 78:1032-1041.

Frost DR. 2016. Amphibian species of the world: an online reference. Version 6.0. Available from: http://research.amnh.org/vz/herpetology/amphibia/

Girard C. 1853. Descriptions of new species of reptiles, collected by the U.S. Exploring Expedition, under the command of Capt. Charles Wilkes, U.S.N. Second part-including the species of batrachians, exotic to North America. P Acad Nat Sci Phila. 6:420-424.

Gosner KL. 1960. A simplified table for staging anuran embryos and larvae with notes on identification. Herpetologica. 16:183-190.

Hu SQ. 1987. Amphibia-Reptilia in Tibet. Beijing: Science Press.

Kaplan RH, King EG. 1997. Egg size is a developmentally plastic trait: evidence from long-term studies in the frog Bombina orientalis. Herpetologica. 53:149-165.

Kilpatrick AM, Briggs CJ, Daszak P. 2010. The ecology and impact of chytridiomycosis: an emerging disease of amphibians. Trends Ecol Evol. 25:109-118.

Kvarnemo C, Ahnesjo I. 1996. The dynamics of operational sex ratios and competition for mates. Trends Ecol Evol. 11:404-408.

Liao WB, Lu X, Jehle R. 2014. Altitudinal variation in maternal investment and trade-offs between egg size and clutch size in the Andrew's toad. J Zool Lond. 293:84-91.

Linnaeus C. 1758. Systema naturae per regna tria naturae: secundum classes, ordines, genera, species, cum characteribus, differentiis, synonymis, locis. Stockholm: Laurentius Salvius.

Longcore JE, Pessier AP, Nichols DK. 1999. Batrachochytrium dendrobatidis gen. et sp. nov., a chytrid pathogenic to amphibians. Mycologia. 91:219-227.

Lu X, Ma XY, Li Y, Fan LQ. 2009. Breeding behavior and mating system in relation to body size in Rana chensinensis, a temperate frog endemic to northern China. J Ethol. 27:391-400.

Lu X, Yu TL, Liang W, Yang CC. 2010. Comparative breeding ecology of two white-bellied redstart populations at different altitudes. J Field Ornithol. 81:167-175.

Lu X, Zeng XH, Du B, Nie C. 2008. Reproductive ecology of Rana kukunoris Nikolskii, 1918, a highaltitude frog native to the Tibetan Plateau. Herpetozoa. 21:67-77.

Lüddecke H. 2002. Variation and trade-off in reproductive output of the Andean frog Hyla labialis. Oecologia. 130:403-410.

Ma XY, Lu X. 2009. Sexual size dimorphism in relation to age and growth based on skeletochronological analysis in a Tibetan frog. Amphibia-Reptilia. 30:351-359.

Ma XY, Lu X, Merilä J. 2009. Altitudinal decline of body size in a Tibetan frog Nanorana parkeri. J Zool Lond. 279:364-371.

Ma XY, Lu X. 2010. Annual cycle of reproductive organs in a Tibetan frog, Nanorana parkeri. Anim Biol. 60:259-271.

Marco A, Kiesecker JM, Chivers DP. 1998. Sex recognition and mate choice by male western toads, Bufo boreas. Anim Behav. 55:1631-1635.

Navas CA. 1997. Thermal extremes at high elevations in the Andes: physiological ecology of frogs. J Therm Biol. 22:467-477.

Navas CA. 2002. Herpetological diversity along Andean elevational gradients: links with physiological ecology and evolutionary physiology. Comp Biochem Physiol A. 133:469-485.

Rabb GB. 1973. Evolutionary aspects of the reproductive behavior of frogs. In: Vial JL, editor. Evolutionary biology of the anurans. Columbia: University of Missouri Press; p. 213-227.

Reading CJ. 1998. The effect of winter temperatures on the timing of breeding activity in the common toad Bufo bufo. Oecologia. 117:469-475.

Reading CJ, Clarke RT. 1983. Male breeding behaviour and mate acquisition in the common toad Bufo bufo. J Zool Lond. 201:237-246. 
Scott WA, Pithart D, Adamson JK. 2008. Long-term United Kingdom trends in the breeding phenology of the common frog, Rana temporaria. J Herpetol. 42:89-96.

Seimon TA, Seimon A, Daszak P, Halloy SRP, Schloegel LM, Aguilar CA. 2007. Upward range extension of Andean anurans and chytridiomycosis to extreme elevations in response to tropical deglaciation. Global Change Biol. 13:288-299.

Seymour RS. 1999. Respiration of Aquatic and Terrestrial Amphibian Embryos. Am Zool. 39:261270.

Seymour RS, Roberts JD. 1995. Oxygen uptake by the aquatic eggs of the Australian frog Crinia Georgiana. Physiol Zool. 68:206-222.

Sinsch U. 1989. Behavioural thermoregulation of the Andean toad (Bufo spinulosus) at high altitudes. Oecologia. 80:32-38.

Smith CC, Fretwell SD. 1974. The optimal balance between size and number of offspring. Am Nat. 108:499-506.

Stejneger L. 1927. A new genus and species of frog from Tibet. J Wash Acad Sci. 17:317-319.

Sullivan BK. 1985. Sexual selection and mating system variation in anuran amphibians of the Arizona-Sonoran desert. Great Basin Nat. 45:688-696.

Telford SR, Van Sickle J. 1989. Sexual selection in an African toad (Bufo gutteralis): the roles of morphology, amplexus displacement and chorus participation. Behaviour. 110:62-75.

Wells KD. 1977. The social behaviour of anuran amphibians. Anim Behav. 25:666-693.

Wells KD. 2007. The ecology and behavior of amphibians. Chicago (IL): University of Chicago Press.

Williamson I, Bull CM. 1995. Life-history variation in a population of the Australian frog Ranidella signifera: seasonal changes in clutch parameters. Copeia. 1995:105-113.

Yu TL, Lu X. 2012. Mating patterns of Bufo raddei from three high altitude populations in southwestern China. Herpetol J. 22:213-217.

Zhang LX, Ma XY, Jiang JP, Lu X. 2012. Stronger condition dependence in female size explains altitudinal variation in sexual size dimorphism of a Tibetan frog. Biol J Linn Soc. 107:558-565. 